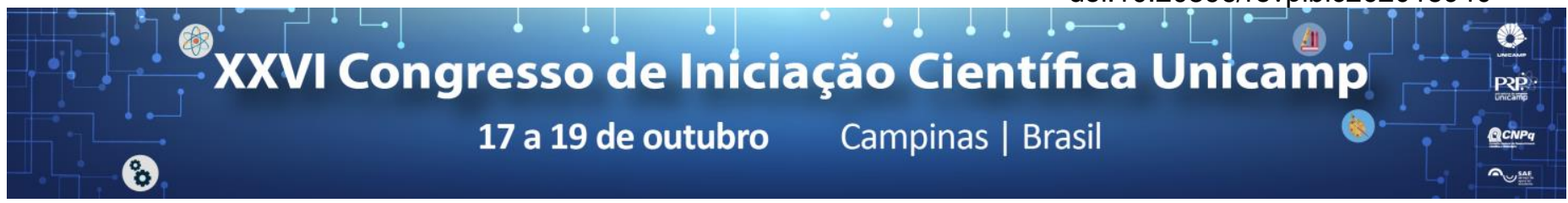

\title{
Sistemas biopoliméricos adicionados de diferentes fontes de amido para a veiculação de compostos bioativos
}

\section{Luíza Moraes Bagnolo*, Flávia Souza Almeida, Karen Cristina Guedes Silva, Ana Carla Kawazoe Sato}

\begin{abstract}
Resumo
Diferentes materiais de parede, constituídos da mistura entre polissacarídeos aniônicos (goma gelana ou alginato) e amidos de fontes distintas (milho, batata ou fosfatado) foram desenvolvidos para microencapsulação de bioativos, viabilizando o uso das estruturas em diferentes aplicações. Observou-se que o amido de batata detém os menores valores das propriedades mecânicas, o que é associado a uma menor percepção sensorial das estruturas quando adicionadas em alimentos, enquanto que o amido de milho é mais barato e de maior disponibilidade, também resultando em sistemas com alta eficiência de encapsulação.
\end{abstract}

Palavras-chave: microencapsulação, gelificação iônica, antocianinas.

\section{Introdução}

A microencapsulação é utilizada para garantir maior proteção e estabilidade de compostos bioativos. A gelificação iônica ${ }^{1}$ é uma técnica bastante utilizada, sendo que o polímero empregado na rede pode influenciar fortemente as propriedades da estrutura. Este trabalho objetivou comparar a mistura entre polissacarídeos aniônicos e amidos de fontes distintas, visando aplicação como sistemas de encapsulação de compostos bioativos. Antocianina foi utilizada como composto modelo a ser encapsulado, devido à alta instabilidade a fatores ambientais $^{2}$ e por apresentar benefícios ao organismo.

\section{Resultados e Discussão}

Para avaliação da macroestrutura, inicialmente foram produzidos hidrogéis constituídos por $1 \%$ de polissacarídeos aniônicos, adicionados de $1 \%$ de amido de diferentes fontes. A inserção de amido promoveu a diminuição da tensão e deformação de ruptura para géis a base de gelana (GEL), e aumentou o índice de consistência $(\mathrm{k})$ para todos os sistemas, deixando-os com o caráter pseudoplástico mais pronunciado $(\downarrow n)$. A capacidade de retenção de água não alterou com a adição de amido para a GEL, mas houve o aumento dessa propriedade para sistemas de alginato (ALG), indicando boa habilidade em reter compostos hidrofílicos. Constatou-se que a adição do amido de batata (AB) resultou em menores valores de propriedades mecânicas independente do material de parede (GEL ou ALG). As partículas constituídas de ALG apresentaram tamanho médio menor que as de GEL, o que foi relacionado ao menor k do ALG, facilitando a formação de gotas durante a atomização. A adição e o tipo de amido influenciaram o diâmetro das partículas: grânulos de amido (corados com iodo) maiores, como 0 de batata, resultaram em partículas de maior diâmetro (Figura 1).

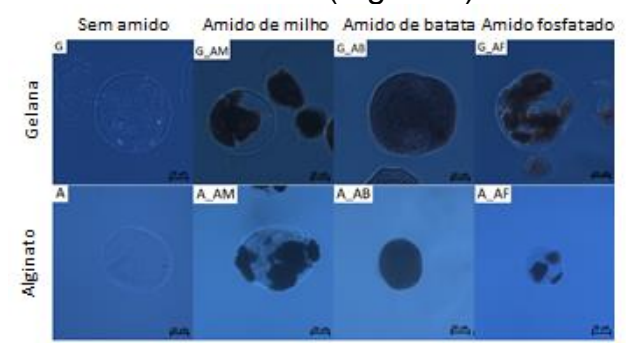

Figura 1. Microscopia óptica das partículas (aumento de 400x).
A microscopia eletrônica (MEV) mostra uma distribuição uniforme dos grânulos, preenchendo os poros da matriz dos géis contendo amido de batata (Figura 2). Tal distribuição não foi observada para as demais formulações, cuja adição de amido não promoveu mudanças perceptíveis na rede. Apesar das diferenças entre as estruturas, alta eficiência de encapsulação de antocianina foi encontrada para todas as formulações (> $80 \%$ ).

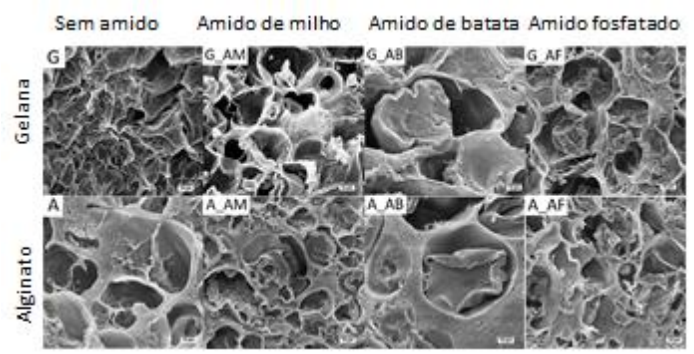

Figura 2. Microscopia eletrônica de varredura (MEV) dos géis (aumento de 2000x).

\section{Conclusões}

A adição de amido na rede biopolimérica permitiu o desenvolvimento de macro e microestruturas de hidrogéis com propriedades distintas: adição de amido de batata resultou nos menores valores das propriedades mecânicas, colaborando para uma menor percepção das estruturas. Já o amido de milho, é uma das fontes com maior disponibilidade, facilitando sua utilização. A alta eficiência de encapsulação mostrou que os sistemas estudados permitem a encapsulação de compostos bioativos, que podem ser aplicados em diferentes alimentos.

Agradeço ao CNPq pelo apoio financeiro.

1SCHOUBBEN, A.; BLASI, P.; GIOVAGNOLI, S.; ROSSI, C.; RICCI, M. Development of a scalable procedure for fine calcium alginate particle preparation. Chem. Eng. Jour, v. 160, n. 1, p. 363-369, 2010.

${ }^{2}$ FERREIRA, D. S.; FARIA, A. F.; GROSSO, C. R. F.; MERCADANTE, A. Z. Encapsulation of blackberry anthocyanins by thermal gelation of curdlan. Journ. of the Braz. Chem. Soc., v. 20, n. 10, p. 1908-1915, 2009. 